\title{
Erratum
}

\section{Erratum to “Zero Divisor Graph of a Lattice and Its Unique Ideal”}

\author{
Rajendra Deore $\mathbb{D}^{1}$ and Pramod Tayade $\mathbb{D}^{2}$ \\ ${ }^{1}$ Department of Mathematics, University of Mumbai, Mumbai 400098, India \\ ${ }^{2}$ Department of Mathematics, Kavayitri Bahinabai Chaudhary North Maharashtra University, Jalgaon 425001, India \\ Correspondence should be addressed to Pramod Tayade; tayade.pramod@yahoo.in
}

Received 2 April 2020; Accepted 3 April 2020; Published 6 June 2020

Copyright (c) 2020 Rajendra Deore and Pramod Tayade. This is an open access article distributed under the Creative Commons Attribution License, which permits unrestricted use, distribution, and reproduction in any medium, provided the original work is properly cited.

In the article titled "Zero Divisor Graph of a Lattice and Its Unique Ideal" [1], there was an error during the production of the article whereby the affiliations were incorrectly attributed to the authors. The correct affiliations for the authors are shown above.

\section{References}

[1] R. Deore and P. Tayade, "Zero divisor graph of a lattice and its unique ideal," Journal of Mathematics, vol. 2019, Article ID 9825495, 5 pages, 2019. 